\title{
A santificação do lugar
}

\section{La santificación del lugar}

\section{The sanctification of places}

\author{
Sheila Castro dos Santos \\ sheila1705@gmail.com \\ Universidade Federal do Paraná \\ Salete Kozel \\ skozel@ufpr.br \\ Universidade Federal do Paraná
}

\begin{abstract}
Resumo: Neste trabalho foram analisadas as especificidades que envolvem o predicativo de santificado dado a um lugar, tendo como exemplo ações aplicadas pela comunidade judaica de Porto Velho - RO. Para tal utilizamos como base teórica Tuan (1980 e 1983), para a caracterização do lugar moldado pela ação humana com envolvimento de sentimentos e caracterizado por símbolos; Halbwachs (1990), para evidenciarmos a ação da memória; Durkheim (2003), para caracterizar a religião como sistema humano de crenças; Gil Filho (2007; 2008a; 2008b; 2009 e 2010), para o uso da Geografia da religião; Cassirer (1994 e 2006), para o entendimento do homem simbólico; e Paul Claval (1979; 2001 e 2002), no conceito de cultura como técnicas de conhecimentos transmitidas de geração para geração.
\end{abstract}

Palavras-Chave: Lugar. Religiosidade. Experiência.

Resumen: En este trabajo fueron analisadas las especificidades que envuelven el predicativo de santificado dado a un lugar, teniendo como ejemplo acciones aplicadas por la comunidad judia de Porto Velho, Rondônia, Brasil. Para tanto utilizamos como base teórica Tuan (1980-1983), para la caracterización del lugar moldado por la acción humana com el envolvimento de sentimentos y caracterizado por símbolos; Halbwachs (1990), para evidenciar la acción de la memoria; Durkheim (2003); para caracterizar la religión con sistema humano de creencias; Gil Filho (2007; 2008a; 2008b; 2009 y 2010); para el uso de la Geografia de la religión; Cassirer (1994 y 2006); para el entendimento del hombre simbólico; y Paul Claval (1979; 2001 y 2002) en el concepto de cultura como técnicas de conocimientos transmitidas de generación en generación.

Palabras Clave: Lugar. Religiosidad. Experiencia.

Abstract: This work analyzed the specificities of the predicative "holy" given to places, having as example actions applied by the Jewish community of Porto Velho, Rondônia, Brazil. For such, were used as theoretical basis: Yi-Fu Tuan (1980 and 1983) to characterize places shaped by human action involving feelings and characterized by symbols; Halbwachs (1990) to evidence the action of memory; Durkheim (2003) to characterize religion as a system of human beliefs; Gil Filho (2007, 2008a; 2008b, 2009 and 2010) for the use of the Geography of Religion; Cassirer (1994 and 2006) for 
the understanding of the symbolic man; and Paul Claval (1979, 2001 and 2002) for the concept of culture and technical knowledge passed from generation to generation.

Keywords: Place. Religiosity. Experience.

\section{INTRODUÇÃO}

Para este trabalho foi utilizado o método o hermenêutico-fenomenológico, pois a união entre hermenêutica e fenomenologia amplia a interpretação das experiências encontradas durante a pesquisa, Paul Ricoeur (2000, p.200) disserta sobre sua base epistemológica para pensar uma hermenêutica fenomenológica, pois para ele "la tradición filosófica a la que pertenezco mediante tres rasgos: está en la línea de una filosofía reflexiva; se encuentra en la esfera de influencia de la fenomenología; pretende ser una variante hermenéutica de dicha fenomenología"

Desse modo, pela fenomenologia pode-se desenvolver a análise do espaço e do lugar, expostos pela narrativa; as vivências podem ser compreendidas, podendo ser observadas conjuntamente com os fenômenos exteriores; e o conhecimento das estruturas de significação e do narrador torna-se importante, pois o que será dito passa a fazer parte da interpretação. Compreendendo que:

la fenomenologia - y más aún la hermenéutica - representa, a la vez, una realización y una transformación radical del propio programa de la filosofía reflexiva. [...] La tarea de la hermenéutica consiste en reconstruir esta doble labor del texto. Podemos ver el camino recorrido desde el primer supuesto, el de la filosofia como reflexión, a lo largo del segundo, el de la filosofía como fenomenología, hasta el tercero, el de la mediación a través de los signos, después a través de los símbolos y, por último, a través de los textos (RICOUER, 2000, p. 200).

E, para entender os processos de apropriação e construção que acontecem quando um lugar é criado; e, nele as relações tornam-se muitas vezes naturais e corriqueiras, no entanto não devem passar despercebidas para o pesquisador. É também no lugar onde ocorre o vínculo com o espaço fenomenológico, nele as experiências do viver, do habitar, do uso e do consumo fazem parte do cotidiano de todos que nele habitam.

Destarte toda representação criada, recriada e reproduzida pelo indivíduo passa pela experiência do vivido; sua forma é percebida primeiramente quando o ser humano reconhece e impõe significado aos objetos, às palavras, às atitudes, etc., pois é o acúmulo de conhecimento e de saberes que nos possibilita realizar as representações.

A partir da análise geográfica buscamos conceituar o lugar santificado, evidenciando de tal modo os elementos de representação indispensáveis ao processo da formação e permanência cultural da comunidade judaica. 


\section{METODOLOGIA}

Ao analisar a metodologia de pesquisa participativa proposta por Geertz (1989), entendemos que ela é caracterizada a partir de aspectos que vão desde o amálgama com o método que o pesquisador se propõe a usar, seguindo para a ida a campo, posteriormente aplicando-se as teorias no momento adequado, após leituras prévias. Desse modo compreendemos que esta é a melhor metodologia a ser utilizada para encontrarmos respostas aos nossos questionamentos.

[...] como no estudo da cultura a análise penetra no próprio corpo do objeto - isto é, começamos com as nossas próprias interpretações do que pretendem nossos informantes, ou o que achamos que eles pretendem, e depois passamos a sistematizá-las -, a linha entre cultura como fato natural e cultura como entidade teórica tende a ser obscurecida. Isso ocorre ainda mais na medida em que a última é apresentada sob a forma de uma descrição do ator das concepções de todas as coisas (GEERTZ, 1989, p.11).

A metodologia participativa objetiva auxiliar o pesquisador a se diferenciar minimamente do grupo a ser pesquisado, aprendendo, dessa maneira, o modo de vida do grupo. E o direciona a fazer parte dele, sem necessariamente o conduzir a promessas de feedbecks sistematizados a partir de projetos ou de atividades que possam sair do metiê do pesquisador. Ela consiste em idas a campo, incluindo os locais de moradia, locais que ocorrem celebrações e reuniões da comunidade, onde o pesquisador pode observar os membros da comunidade e vivenciar seu dia a dia de maneira científica, podendo participar das manifestações culturais. Ela visa ainda o aprofundamento do conhecimento dos símbolos e busca compreender a importância dos aspectos culturais da comunidade estudada a partir da vivência e de suas representações cultural, material e imaterial. Com a proximidade que esse tipo de pesquisa proporciona, poderemos perceber as diferentes formas de compreensão do mundo dos membros da comunidade, como bem expõe Geertz (1989).

As indagações e reflexões presentes neste artigo foram consequência de estudos realizados durante alguns anos, com o objetivo de evidenciar a santificação do lugar a partir da necessidade do homem de experienciar os ritos religiosos conforme a religião a que pertence. Essa utilização do lugar transformando-o tem uma existência social, material e fenomenológica, como informa Claval (2001):

[...] grupos humanos aprendem, pois, a explorar o espaço e a encerrá-lo em sistemas de representações que permitem pensá-lo. Batizando os lugares e os meios, eles os transformam em objetos de discurso. Impondo-lhes suas marcas e instituindo-os, fazem deles uma categoria social. [...] através da maneira como os grupos humanos o concebem, analisam e percebem suas possibilidades, e através das técnicas que permitem explorá-lo: a mediação tecnológica é essencial nas relações dos grupos humanos com o mundo que os rodeia (CLAVAL, 2001, p.218-219. Grifos nossos). 


\section{LUGAR PARA SANTICAR}

Nas igrejas pentecostais ou neopentecostais como Assembleia de Deus, Quadrangular, Universal do Reino de Deus, Mundial, Da Graça de Deus, etc., o uso do lugar é percebido de acordo com a necessidade de novas igrejas para cooptar ou manter seus fieis. Essa necessidade de novos lugares para serem sacralizados para manutenção do rito é percebida por Claval (2001, p. 154) pois "é bom escolher aqueles impregnados de sacralidade; se não, é necessário consagrá-lo".

Para essas instituições cujo local escolhido pode um dia ter sido um bar, supermercado, loja ou outro ambiente, utilizado para fins comerciais ou privados, a mudança ocorrerá seguindo algumas observações, pois “o espaço sagrado não é feito simplesmente de lugares públicos: ele comporta altares privados, fundamentais em muitos sistemas religiosos" (CLAVAL, 2001, p. 154).

Dessa maneira, percebemos que são várias as funções, assim como são múltiplos os lugares onde se desenvolvem a socialização entre indivíduos religiosos, e estes são escolhidos e separados para que possam propiciar experiências com o sobrenatural. Para que haja coerência e sentido para a propensa função, há um preparo do lugar para seu uso. Com a participação de alguns membros da comunidade religiosa, o lugar é envolto por fenômenos que conduzem o indivíduo religioso a vivenciar a espacialidade sagrada incorporando alguns costumes peculiares de sua religião.

O lugar é privado ao culto e adoração ao Deus, com altares, objetos sagrados; precisa ser preparado e não deve ser profanado. Esse deve ser sempre o ponto entre o indivíduo e o seu Deus; é o lugar onde a intimidade pode ser buscada junto com outros que fazem parte da mesma comunidade de fieis, e essa intimidade é respeitada por quem a ele pertence.

No judaísmo o lugar é santificado de maneira diferente, pois dependendo do fim para o qual o espaço foi utilizado anteriormente, não poderá ser uma sinagoga, pois o lugar tem um significado importante e é onde a fé e a cultura serão evidenciadas, demonstrando sua reverência a seus antepassados. O lar judaico também é revestido de simbolismo, com divisões, limites e costumes para que seja configurado para adoração e manutenção da cultura de seus antepassados. Para Bollnow (2008) o lar é onde o sentimento de proteção é reproduzido, mas ele também é elaborado com repartições que definirão essa proteção, e a evocação mítica e cultural de seus moradores. Logo a,

"A habitação [...] é o universo, que o homem constrói para si ao reproduzir a criação exemplar pelos deuses, a cosmogonia." Nisso consiste a relação espetacular e bem fundamentada entre criação do mundo e construção da casa: "Quem ordena um espaço repete o trabalho exemplar dos deuses" [...] Atravessar a porta é atravessar o limiar, como via de regra chamamos a soleira, tábua inferior da porta. O limiar denota por esse motivo, de modo ainda mais definido, a fronteira entre o dentro e o fora. Transpor o limiar é, por isso mesmo, também com muita frequência, na língua erudita, um pars pro toto (a parte pelo todo) para entrar na casa. Cumprimenta-se o nobre hóspede no limiar de sua casa (BOLLNOW, 2008, p. 153-168). 
Na casa a intimidade é vivida, nela "toda grande imagem simples revela um estado de alma". A casa, mais ainda que a paisagem, é "um estado de alma". Mesmo reproduzida em seu aspecto exterior, ela fala de uma intimidade (BACHELARD, 2000, p. 84).

A casa para um judeu é a extensão de seu corpo, por ser o lugar onde pode demonstrar ainda mais seus dogmas; é dentro da casa que o judeu vai realizar a maior parte dos ritos para justificar e manter a postura de seus antepassados. A casa não é algo à parte, ela faz parte dele; ao possuí-la, o judeu deve fazer os ritos necessários para que ela seja abençoada por Deus e possa refletir sua confiança, sua fé nos preceitos da cultura judaica.

Por isso, entender onde e como se dá a construção do lugar santificado e suas especificidades é uma maneira de a Geografia da religião identificar e entender as formas religiosas que o consagram. Devemos também compreender a diferença entre o espaço e o lugar. Para Tuan (1983) o lugar é percebido quando torna-se inteiramente familiar, deixando, desse modo, de ser espaço para ser lugar.

As diferenças de amplitude e liberdade entre esses dois conceitos têm certas nuances a serem definidas. Moldar o lugar com predicados que o tornem santificado para uso específico de uma religião deve ser entendido e evidenciado. E compreender como o lugar é escolhido para depois ser santificado na religião judaica é uma tarefa que requer tempo e uma pesquisa participativa minuciosa, pois é no lugar que vão se materializar os aspectos cultural e religioso. Em alguns lugares não há a sinagoga, contudo há da mesma maneira a criação de seu lugar de reunião e morada, passando este a ser seu ponto de segurança, onde acontecem os ritos, os quais são passados de uma geração a outra.

A abordagem cultural da religião é outro ponto a ser observado. Estudos realizados por pesquisadores ligados a essa ótica de raciocínio evidenciam a existência do "espaço sagrado", que será sempre diferente do espaço "profano" ou "mundano", em seus valores simbólicos. Essa diferença pode ser percebida em âmbito mais restrito como no lugar. Paul Claval (2008), ao levar em conta a experiência diferenciadora do espaço sagrado, afirma que neste existe carga emotiva, que proporciona o encontro com o sobrenatural ou com a divindade:

Um espaço sagrado difere do espaço profano porque tem uma carga emotiva muito forte: ele aparece ao mesmo tempo como muito atrativo e ameaçador, porque está marcado pela presença da divindade ou de forças sobrenaturais. No coração do espaço sagrado existe muitas vezes uma zona tão perigosa que os sacerdotes podem visitar. [...] A vivência religiosa não se resume ao sentido do sagrado. Ela também integra o recolhimento, a meditação, a oração, a comunhão através do canto ou da dança, o êxtase (CLAVAL, 2008, p. 21. Grifos nossos).

A integração religiosa é quase sempre direcionada a um lugar específico, pois o lugar é um dos elementos para que haja comunhão com o sobrenatural ou com a divindade. Na contemporaneidade, com a nova perspectiva da Geografia cultural e da Geografia da religião, tanto a cultura como a religião são interpretadas com maior intensidade nas especificidades que cada sociedade possui. A cultura possui variáveis diferentes de sociedade para sociedade. Segundo Paul Claval (2001) a cultura é: 
a soma dos comportamentos, dos saberes, das técnicas, dos conhecimentos e dos valores acumulados pelos indivíduos durante suas vidas e, em uma outra escala, pelo conjunto dos grupos de que fazem parte. A cultura é herança transmitida de uma geração a outra. Ela tem suas raízes num passado longínquo, que mergulha no território onde seus mortos são enterrados e onde seus desuses se manifestam. Não é, portanto, um conjunto fechado e imutável de técnicas e de comportamentos (CLAVAL, 2001, p. 63. Grifos nossos).

Buscamos seguir nessa sociabilização de cultura e religião e nos amparamos em Durkheim, que conceitualiza religião como:

[...] um sistema solidário de crenças seguintes e de práticas relativas a coisas sagradas, ou seja, separadas, proibidas; crenças e práticas que unem na mesma comunidade moral, chamada igreja, todos os que a ela aderem (DURKHEIM, 2003, p. 79, grifos nossos)

No contexto atual Gil Filho (2008a) trabalha a Geografia da religião, envolvendo-a diretamente em uma discussão da fenomenologia, ou seja, o sentido e o significado das emoções demonstradas pelo fiel, ao estruturar sua vida, seu espaço e seu lugar de morada a partir da sua fé, do credo de sua religião.

As marcas deixadas pelo homem e no homem pela sua religiosidade são estudadas pela Geografia da religião para compreender o homo simbolicus. É próprio da humanidade dar significado e buscar sentido para tudo o que faz, pois essa característica de construção simbólica é intrínseca ao ser humano e, por isso, o sagrado é apresentado no plano da linguagem e da percepção:

[...] o espaço sagrado permite um esquema no qual os diversos elementos religiosos podem ser postos em relações mútuas. Há por assim dizer, a espacialização daquilo que não é de natureza espacialmente qualitativa. Disso compreendemos que o espaço sagrado é estrutural, pois o homem religioso define suas hierarquias qualificativas reveladoras de suas práticas religiosas, ao passo que o profano é apenas funcional. [...] Na espacialidade das representações simbólicas, o espaço sagrado é apresentado no plano da linguagem, na medida em que as percepções religiosas são conformadas a partir da sensibilidade das formas tempo e espaço. Nesse sentido, as coisas religiosas da expressão empírica são configuradas como formas da intuição explicitadas em um processo de desenvolvimento rumo às representações (GIL FILHO, 2008a, p. 72-73).

A "espacialidade religiosa" é um ponto importante, pois cada religião impõe empiricamente sensações e sentimentos únicos e múltiplos a seus membros. O significado dado fica evidente a partir do sentimento que é aflorado e das manifestações que são exteriorizadas; logo, a crença e a religião são sentidas interna e externamente por quem a pratica.

Com a sensação inebriante de que os sentimentos gerados no âmbito do sagrado serão sentidos cada vez mais intensamente, o homem externaliza atitudes. Condutas que possam conduzi-lo de volta a sentir a presença do sobrenatural ou da divindade. 
O crescimento nas pesquisas em Geografia vem possibilitando novas perspectivas no desenvolvimento das pesquisas geográficas. Nesse sentido a Geografia nos possibilitou a pesquisa em uma comunidade que se une por identificação religiosa e cultural tal qual é a comunidade judaica.

Usar amálgamas disciplinares capazes de possibilitar o entendimento e a compreensão dos símbolos da religião pesquisada é um dos pontos a ser aprofundado no decorrer da pesquisa, pois a atenção primordialmente será voltada para os indivíduos em seu lugar de culto.

Entendemos que a crença ajuda as pessoas a suportarem as mais diversas situações, seja ela material ou imaterial ${ }^{1}$.

A sensação de conseguir vencer os obstáculos pelo favor de seu "Deus" envolve o homem tomando-o de tamanha esperança, que, ao acreditar, ele age envolto pela aura de poder sobrenatural. Esse protofenômeno que transcende no homem é criado através do conhecimento simbólico da deidade.

A partir do conhecimento da deidade o homem modifica seu ato. Forma novas concepções, cria esculturas, gravuras, histórias, modifica a paisagem para engrandecer seu Deus. Como diz Gil Filho (2009, p. 1) a "religião manifestava-se como produto da prática humana, como expressões da cultura religiosa e como um campo de motivações materializadas na paisagem".

Na perspectiva de "lugar" construído com atitudes simbólicas, inconscientes e conscientes, vividas pela comunidade, observa-se a imposição do valor simbólico dado ao lugar do templo, da casa e da sinagoga pela comunidade judaica.

Tuan (1983) e Carlos (1996) consideram lugar o resultado do uso habitual, que adquire densidade de significado e estabilidade, sendo ele capaz de reter a atenção humana para sua práxis existencial.

No entanto, Tuan (1983) procurou entender o lugar a partir da experiência pessoal e coletiva com a percepção de lugar como mítico-conceitual, que é ligado à experiência humana. A casa, o templo, o recinto de trabalho ou de lazer são lugares sentidos e palpáveis, onde nos deslocamos; são espaços moldados e sentidos pelo corpo, nas palavras de Tuan:

O espaço mítico é também uma resposta do sentimento e da imaginação às necessidades humanas fundamentais. Difere dos espaços concebidos pragmática e cientificamente no sentido que ignora a lógica da exclusão e da contradição. É um mundo de significado organizado é essencialmente estático [...] possuem significados, símbolos bem visíveis como arquitetura, arte [...] existem de maneira diferente (TUAN, 1983, p. 112-198).

Ao identificar-se com o lugar, o homem lhe impõe valores simbólicos próprios de seu interior. Enquanto o espaço, nas palavras de Tuan: “é mais abstrato do que 'lugar'. O

1 Entende-se por material as perdas móveis que levam muitos indivíduos a procurarem ajuda sobrenatural para conquistarem aumento em seus bens e por imaterial, toda forma emocional que conduz o indivíduo a buscar ajuda para suportar a dor ou por motivo de agradecimento. 
que começa como espaço indiferenciado transforma-se em lugar à medida que o conhecemos melhor e o dotamos de valor" (TUAN, 1980, p. 6).

Com o passar do tempo os sentimentos de afeto para com o ambiente material do lugar vão sendo incorporados pela comunidade judaica. Esses são primordiais para a caracterização de pertencimento ao lugar; poder reconhecer e possuir esse sentimento de pertencimento por determinado lugar é o elo afetivo, chamado de topofilia por Tuan (1980), que é demonstrado pelo membro dessa comunidade ao construir seu lar, posicioná-lo e organizá-lo de modo que possa sempre sentir-se em contato com seu "Deus" ou com a cultura ensinada por seus ancestrais.

Cada indivíduo produz pensamentos, ações, experiências, os quais terão conexão direta ou indireta com o lugar onde operam, onde o indivíduo vivencia as experiências em comunidade ou no íntimo da família.

Essas experiências vividas advindas do espaço simbólico são redes intensas que se confundem com o próprio lugar e devem ser compreendidas por meio de rede teórica que busca, através das interpretações dos textos e mediante idas a campo, apreender e compreender a experiência vivida por essa comunidade na construção de seu lugar de morada.

Entender esse lugar vivido transcende os fatores materiais, as experiências fenomenológicas vividas no dia a dia pelos indivíduos, pois é imprescindível compreender o corpo e suas características, especificidade, influência, no lugar utilizado, habitado e vivido.

Ora o conjunto do sistema religioso, público ou privado, é composto por pequenas porções de atitudes humanas, advindas das experiências adquiridas com o passar do tempo. Deste modo, observa-se que Halbwachs (1990) e Tedesco (2004) concordam que essas experiências advêm da "memória" que se forma a partir de compilações de informações adquiridas por pessoas próximas, por mídias ou outros meios de informação, que chegam ao indivíduo formando-o.

Essas atitudes vividas são relatadas no cotidiano pela fala, por memórias, nas modificações que os indivíduos fazem em seu espaço vivido e no sentimento para com o lugar experienciado, pois:

Só temos capacidade de nos lembrar quando nos colocamos no ponto de vista de um ou mais grupos e de nos situar novamente em uma ou mais correntes de pensamento coletivo [...] A memória coletiva não explica todas as nossas lembranças e talvez ela não explique por si mesma a evocação de qualquer lembrança. Haveria então na base de toda a lembrança, o chamado a um estado de consciência puramente individual que para distingui-lo das percepções onde entram tantos elementos do pensamento social. Admitiremos que se chame intuição sensível [...] A memória individual de um lado é no quadro de sua personalidade, ou de sua vida pessoal, que viriam tomar lugar suas lembranças: aquelas que lhes são comuns com outras não seriam consideradas por ele a não ser sob o aspecto que lhe interessa, na medida em que ele se distingue delas (HALBWACHS, 1990, p. 36-37). 
A memória coletiva, por meio da narração, reafirma sua força de transmissão, pois, para continuar a recordar, é necessário que cada geração transmita o fato passado para que possa se inserir nova vida em uma tradição comum. Desse modo, o acolhimento do conteúdo narrativo e a necessidade de recordá-lo tornam-se um dever. $\mathrm{O}$ ato narrativo, na medida em que é possível sua elaboração e apropriação, constrói um sentimento de identidade coletiva do grupo e um sentido de pertencimento dos indivíduos; ajuda a conhecer o grupo e a organizar as próprias relações internas (TEDESCO, 2004, p. 36).

Mesmo levando se em conta que a memória do indivíduo é formada pelo contexto social em que vive, Tedesco (2004) evidencia a busca pela individualização como uma constante na vida do homem. Por isso as escolhas religiosas ou os gostos mais diversos se dão de diferentes maneiras de um indivíduo para outro.

Um ponto que é evidenciado a partir da interação do homem com sua religião são as características atribuídas ao lugar, que irão acompanhá-lo, mesmo quando este não estiver presente; ele será unido ao lugar pela memória. O lugar também contém signos e símbolos da cultura e da religião do indivíduo, que lhe moldaram. Por isso, o lugar santificado evidenciará as características da religião ou crença que lhe santificaram para que permaneça santificado.

Há diferenças entre o lugar sagrado e o lugar santificado. O primeiro, além de ser único para cada crença, tem sua criação atribuída ao sobrenatural; ele não possui um estado anterior; ele sempre foi, é e será sagrado. Sua unicidade lhe atribui áurea sobrenatural advinda diretamente da "divindade". Além de ser único para cada religião, o sagrado é vedado à profanação, pois ele não foi secular, não teve em nenhum momento utilização que não fosse sacra. A palavra sagrado, segundo o dicionário Houaiss (2009) "é algo relativo ou inerente a Deus, a uma divindade, à religião, ao culto ou aos ritos; sacro, santo, o sagrado é o que recebeu a consagração, que se sagrou. É o que não se deve infringir; inviolável, o que não se pode deixar de cumprir, é muito estimado, em que não se deve tocar ou mexer". Já o santificado é aquilo "que se santificou; que adquiriu a condição de santo"; sua existência começa quando adquire o predicativo que anteriormente não lhe era atribuído, o santificado já teve seu momento comum e poderá voltar a sê-lo, se o uso do atributo lhe for retirado.

A prática existencial humana já é por si mesma atravessada pelo sistema simbólico, do qual, para Cassirer (1994, p. 50), todos os seres humanos são partícipes, pois “a linguagem, o mito, a arte e a religião são partes deste universo. Estes vários fios que tecem a rede simbólica formam uma teia emaranhada da experiência humana", que nos une com especificidade cultural e religiosa. Desse modo, entendemos que o homem está imerso em redes simbólicas, e por meio dos mecanismos da simbolização atribui significados às diferentes experiências vividas.

A estrutura do pensamento religioso, como informa Gil Filho (2008), possui as formas de apreensão da realidade experienciada pelos crentes. No caso dos judeus é possível caracterizá-los como adeptos da religião ou da cultura. Essa comunidade incorpora dentro de seu cotidiano alguns elementos dos costumes locais. Em sua vivência, também possui em comum "cultura" e "religião" carregadas pelo simbólico. A distinção e 
a especificidade entre cultura e religião é evidenciada para que haja compreensão de que há judeus que praticam os ritos, são partícipes da mesma religião, acreditam na unicidade de seu Deus e fazem as comemorações. Esses creem em sua religiosidade; contudo há judeus que participam dos ritos para que sua cultura e a história de seus antepassados possam permanecer viva, mas não acreditam na existência de Deus.

Entendemos que o conhecimento experiencial percorre todas as religiões, por serem formadas por homens e mulheres que vivem sua vida de acordo com sua fé. Logo, as religiões necessitam da abordagem geográfica para que haja entendimento de como se dá sua organização espacial, como são instituídas suas hierarquias pela crença, como santificam o lugar para o culto e como aplicam sua fé em seu cotidiano. Cassirer evidencia a composição do social pelas especificidades humanas, pois:

[...] temos como natural e evidente que o mundo se divida, para a nossa percepção e contemplação, em configurações individuais incisivamente delineadas, cada qual dotada de limites espaciais perfeitamente determinados e, por seu intermédio, de sua individualidade específica. Apesar de as vermos como um todo, este todo se compõe de unidades claramente distintas, que não se misturam entre si, mas possuem cada uma sua peculiaridade, que se aparta nitidamente da peculiaridade das demais. Para a visão mítica, porém, nem sequer estes elementos singulares são dados separadamente desde o início, mas ela deve conquistá-los ao todo, sucessiva e paulatinamente. Por isso, a apreensão mítica foi chamada de apreensão "complexa", para melhor distingui-la de nosso modo de ver analítico-abstrato (CASSIRER, 2006, p. 26).

O conhecimento dos signos e significados que cada religião transmite ao seu séquito faz-se necessário para que o geógrafo possa compreender o ponto de intersecção do simbólico em suas espacialidades.

A especificidade do lar judaico é percebida quando a casa é construída por proprietários judeus religiosos, pois eles enterram alguns adereços, colocam a mezusah ${ }^{2}$ na porta da casa para identificação do lar, usam a hamsa ${ }^{3}$ como amuleto de proteção, assim como a mezusah. Os compartimentos da casa são organizados para que haja respeito pelos mandamentos, ou seja, pelas mitzvot, ${ }^{4}$ e estas são observadas de acordo com a crença de cada indivíduo da comunidade; a dispensa ou o armário na cozinha são organizados como manda os costumes de seus ancestrais, lembrando, assim, da obediência ao kashrut, ${ }^{5}$ que é seguido no lar ou fora dele.

Na perspectiva da Geografia da religião averiguamos que na região Norte do país houve uma forte incorporação do judaísmo durante o século XVIII período em que migraram para aquela região Benchimol (1998) afirma que é muito clara a "assimilação" de grande massa de judeus na região Norte. Devido à ruptura das práticas culturais e

\footnotetext{
2 Amuleto usado para proteção da casa.

3 Amuleto usado para indicar a presença de Deus na casa ou dentro da pessoa que a usa.

4 Mandamentos, votos e obrigações que o judeu deve praticar.

5 Prática alimentar.
} 
religiosas, ele denominou a massa que não sabe de sua descendência judaica no Norte de "judeus-caboclos":

Um número muito grande de famílias judaicas desapareceu para o judaísmo, pois seus descendentes no interior foram incorporados e integrados a massa anônima dos caboclos empobrecidos, que adotaram o culto católico, evangélico, espiritista e até umbandista, esquecendo de vez as suas origens ancestrais judaicas. Pelos nossos cálculos existem, hoje, em toda a Amazônia, cerca de 283.859 judeus-caboclos descendentes dos sefaraditas e forasteiros de Marrocos e de askenazitas europeus, cujas primeiras levas de migrantes chegaram a região a partir de 1810 (BENCHIMOL, 1998, p. 175).

A reprodução e mudança das práticas culturais e religiosas tornaram-se evidente e dependeram do fator humano e do fator geográfico, pois ocorreram em razão da necessidade humana de permanência no lugar em que as modificações ocorreram. Contudo nem todos deixaram suas práticas e alguns continuaram a perpetuar sua cultura e religiosidade em seu lar.

A religião almejada vai conduzir o homem a moldar sua realidade externa e objetiva às suas normas; ele usa as palavras e os signos como instrumentos modeladores do espaço para a configuração íntima do seu lugar. Ao apresentar o homem religioso, Gil Filho escreve que ele:

[...] imprime ao mundo sensível uma descontinuidade que reclassifica qualitativamente os objetos. Ao sacralizar o mundo, o homem religioso atribui a significação plena de um espaço sagrado em oposição a todo o resto, como sendo sem forma e sentido (GIL FILHO: 2008a, p. 16).

A necessidade de lugar ou lugares específicos para a realização dos ritos e costumes possui valores que lhes são agregados pelos indivíduos, que constroem ou que os tomam para si um lugar. Alterando seu modo de vida, dando algumas ressignificações aos seus costumes, caracterizam o lugar com adjetivos, atributos fenomenológicos que transcendem a natureza comum. Dessa maneira o lugar adquire valor simbólico único para a comunidade, o qual será sempre afirmado ou reafirmado por ela.

A mudança espacial não elimina o mito, ${ }^{6}$ pois ele continua mesmo passando por mudanças e transformações que serão inseridas ou criadas de acordo com o lugar em que ele é materializado.

A linguagem é outro elemento importante para a manutenção do mito; ela também é usada para expressar a afirmação social, assim como é utilizada pelo judeu para afirmar sua genealogia e sua identidade. Ela é evocada para indicar seus antepassados, algumas vezes, usando figuras de linguagem ou metáforas, para identificar-se com seus ascendentes, pois, para Cassirer (2006, p. 29), a linguagem é a expressão humana que “dentre mito, o espaço é dividido em regiões tanto intuitivas como identitárias"' (GIL FILHO, 2009, p. 4). 
a massa de expressões individuais equivalentes, aos poucos produz uma expressão, que logo estende seu domínio sobre um número sempre crescente de casos até que, por fim, se presta a abranger todos eles e pode tornar-se conceito genérico".

Como humanos necessitamos representar de alguma maneira o que sentimos, conhecemos e experienciamos. Essa necessidade de representar pode ser caracterizada como uma premissa humana, como informa Durkheim (2003), que ocorre por vivemos em sociedade e dessa forma necessitamos nos comunicar com outros seres humanos:

As necessidades da existência nos obrigam a todos, os crentes e incrédulos, a representar de alguma maneira as coisas no meio das quais vivemos, sobre as quais a todo o momento emitimos juízos e que precisamos levar em conta em nossa conduta (DURKHEIM, 2003, p. 4).

Dessa necessidade de exteriorizar com representações ou linguagem, notamos que, quando o lugar é criado ou modificado com uma sequência reconfigurada para o contato com o sobrenatural, ele é modificado de forma mítica, para o encontro com a entidade mítica.

Na maioria das vezes o mito não perde sua essência, porém algumas vezes ele, para sobreviver, é transformado de acordo com a necessidade encontrada no lugar onde o indivíduo está; por isso, o mito é atualizado com a prática. Os judeus, para assegurarem que seus descendentes continuassem a realizar os rituais que lhes eram mandamentos divinos, transformam o lar judaico em lugar de estudo e adoração a $\mathrm{IHVE}^{7}$ O lugar da casa é santificado para a presença do "Eterno".

\section{CONCLUSÃO}

Todas as formas de utilização do lugar para a comunhão com o sobrenatural podem ser identificadas, primeiramente com a separação do uso comum, e posteriormente com rituais específicos aos dogmas de determinada religião. As abordagens realizadas neste artigo devem ser ampliadas futuramente, com sistematização das informações, uma vez que aqui foi preciso delimitarmos a abordagem sobre a discussão da santificação do lugar para adoração/culto, tendo como exemplificação a comunidade judaica.

Somos sabedores de que as riquezas simbólicas que não foram evidenciadas necessitam de aprofundamento nos estudos, no entanto ficou evidenciado a utilização e a transformação simbólica do lugar para a religiosidade.

\section{REFERÊNCIAS}

BACHELARD, G. A poética do espaço. São Paulo: Martins Fontes, 2000.

BENCHIMOL, S. Judeus no ciclo da borracha. Manaus: Uerj, 1994.

7 O tetragrama criado por Moisés para evitar que os judeus pronunciassem o nome de Deus. 
Eretz Amazônia: os judeus na Amazônia. Manaus: Valer, 1998.

BLAY, E.A. Judeus na Amazônia. In SORJ, B. (Org.). Identidades judaicas no Brasil Contemporâneo. Rio de Janeiro: Imago, 1997. p. 33-66.

BOLLNOW, O. F. O homem e o espaço. Curitiba: UFPR, 2008.

CARLOS, A. F. A. O lugar no/do mundo. São Paulo: Hucitec, 1996.

. Novos caminhos da Geografia. São Paulo: Contexto, 2002.

CASSIRER, E. Ensaio sobre o homem: introdução à uma filosofia da cultura. São Paulo: Martins Fontes, 1994.

Linguagem e mito. São Paulo: Perspectiva, 2006.

CLAVAL, P. Espaço e poder. Rio de Janeiro: Zahar, 1979.

. A Geografia cultural. Florianópolis: Ed. UFSC, 2001.

$19-28$.

. A volta do cultural na Geografia. In Mercator - Revista de Geografia da UFC, ano 1, n. 1, 2002. p.

. A evolução recente da Geografia cultural de língua francesa. Revista GeoSul, Florianópolis, v. 18, n. 35, p. 7-25, jan./jun. 2003.

. Apresentação. In: SILVA, J. da C.; KOZEL, S.; GIL FILHO, S. F. (Orgs.). Da percepção e cognição à representação: reconstruções teóricas da Geografia cultural e humanista. São Paulo: Terceira Marge, 2007. p. 9-14.

Uma, ou algumas, abordagem(ns) cultural(is) na Geografia humana? In: SERPA, Angelo (Org.). Espaços culturais: vivências, imaginações e representações. Salvador: EDUFBA, 2008.

DURKHEIM, É. As formas elementares da vida religiosa. São Paulo: Martins Fontes, 2003.

GEERTZ, C. J. A Interpretação das Culturas. Rio de Janeiro: LTC, 1989.

GIL FILHO, S. F. Notas para uma Geografia das formas simbólicas em Ernst Cassirer. In: REVISTA CRISE, PRÁXIS E AUTONOMIA: ESPAÇOS DE RESISTÊNCIA E DE ESPERANÇAS - ESPAÇO DE SOCIALIZAÇÃO DE COLETIVOS. Anais ENG, Porto Alegre, 2010.

. Espaço sagrado: estudos em Geografia da religião. Curitiba: XIBIPEX, 2008a.

Espacialidade do espaço sagrado. In: SERPA, Angelo (Org.). Espaços Culturais: vivências, imaginações e representações. Salvador: EDUFBA, 2008b.

. Geografia da religião: reconstruções teóricas sob o idealismo crítico, 2009. Disponível em: <www. geografiaufpr.br/neer>. Acesso em: 13/03/2011.

. Geografia da religião: reconstruções teóricas sob o idealismo crítico. In: SILVA, J. da C; KOZEL, S; GIL FILHO, S. F. (Orgs.). Da percepção e cognição à representação: reconstruções teóricas da Geografia cultural e humanista. São Paulo: Terceira Marge, 2007. p. 207-222.

Geografia cultural: estrutura e primado das representações. In: Revista Espaço e Cultura, Rio de Janeiro, Uerj, n. 19-20, 2005, p. 51-59.

HALBWACHS, M. A memória coletiva. São Paulo: Editora Revista dos Tribunais, 1990.

HOUAISS. Dicionário eletrônico da língua portuguesa 3.0. Versão 2009.

RICOUER, P. Narratividad, fenomenologia y hermenêutica. In revista analise n. 25, 2000. p. 189-207.

SILVA, J. da C.; KOZEL, S.; FILHO, S.F.G. (Orgs.). Da percepção e cognição à representação: reconstruções teóricas da Geografia cultural e humanista. São Paulo: Terceira Margem, 2007.

SORJ, B. Sociabilidade brasileira e identidade judaica. In: SORJ, B. (Org.). Identidades Judaicas no Brasil Contemporâneo. Rio de Janeiro: Imago, 1997. p. 9-32.

SORJ, B. (Org.). Identidades judaicas no Brasil contemporâneo. Rio de Janeiro: Imago, 1997. 
TEDESCO, J. C. Nas cercanias da memória: temporalidade, experiência e narração. Passo Fundo: UPF: Caxias do Sul: Educs, 2004.

TUAN, Yi-fu. Topofilia: um estudo da percepção, atitudes e valores do meio ambiente. Rio de Janeiro: Difel, 1980. Espaço e lugar. São Paulo: Difel, 1983.

VAN GENNEP, A. Os ritos de passagem. Petrópolis: Vozes, 1978.

Recebido em 08/10/2012

Aceito para publicação em 22/10/2013 